INTERNATIONAL DESIGN CONFERENCE - DESIGN 2018

https://doi.org/10.21278/idc.2018.0425

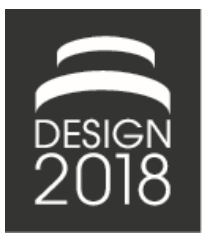

\title{
PLANNING OF SMART SERVICES BASED ON A REFERENCE ARCHITECTURE
}

\author{
M. Rabe, L. Asmar, A. Kühn and R. Dumitrescu
}

\begin{abstract}
Smart services are digital services that use data of physical products to create value for users like automatic reordering of consumables. New capabilities of technical systems enable smart services and changing business models like pay-per-use require smart services. The reference architecture considers both and supports the planning of new services around an existing product of manufacturing companies. The contributions shows an approach of smart service building blocks and their combination based on a consistency assessment.
\end{abstract}

Keywords: product-service systems (PSS), service oriented design, cyber physical systems, internet of things (IoT), business models

\section{Introduction}

Manufacturing companies are currently pushing the transformation from product manufacturer to service provider (Herterich et al., 2015). A key driver is the further development of the capabilities of technical systems. The systems are increasingly networked, able to collect more data and interact more intensively with users. One way to take advantage of these capabilities are smart services. The idea is to implement digital services based on the data of a physical product in order to generate additional value. Examples include predictive maintenance or automated reordering of consumables.

Another driver of the shift from manufacturing to services are the changing needs of the markets. Customers do not want to own products; they just want to use them. Digital platforms make it much easier to share physical products. The use of the products can be offered as a service on platforms. The possibilities for smart services for existing products are manifold and depend on the individual situation of a company and its products. Some companies already offer smart services, but there are only few approaches to systematically plan and design them. For the planning of smart services it is important to limit the solution space in order to leverage the most promising potentials among the many possibilities. The digitization of products and services means more opportunities for a horizontal integration but leads to a high degree of complexity (Kuhlenkoetter et al., 2017).

This contribution structures the topic area and shows a concept of a reference architecture that supports the planning of smart services for an existing product. The concept shows the essential elements and their links to enable a planning from a technological and market perspective.

\section{Smart services as a new market offering for manufacturing companies}

The term was popularized in 2005 by an article of Allmendinger and Lombreglia (2005), which describes a new type of service that is linked to an intelligent object and is provided by this object. Intelligent objects can record, process and communicate their own status and the status of the environment in order to generate information which is the basis for the service. Smart services are thus 
an integral part of a product and go beyond usual product-related services. The authors define seven possible services. Figure 1 illustrates this concept and shows the examples.

Intelligent Object

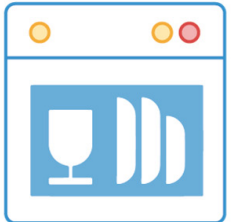

e.g. Dishwasher

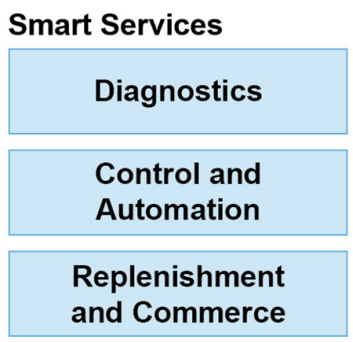

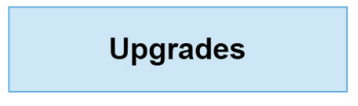

Profiling and Behavior Tracking

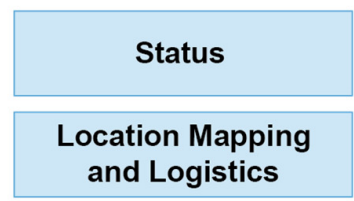

Figure 1. Concept and examples for smart services following Allmendinger and Lombreglia (2005)

Further research is based on the concept of Allmendinger and Lombreglia (2005). Wünderlich et al. (2015) differentiate between smart services in terms of target groups (individual users, groups, companies). Riegg et al. (2016) describe the different abilities with regard to self-description, contextual integration, learning ability and proactive behaviour. Porter and Heppelmann (2015) describe different stages that build on each other: monitoring, control, optimization and automation. The study Smart Service Welt emphasizes user integration and individual deployment (Kagermann et al., 2015).

\subsection{Definition of the term}

Our following definition (Figure 2) attempts to give a basic understanding of the term in order to follow the idea of this contribution. In the literature, there are many definitions, which are similar but do not completely agree and partly contradict each other.

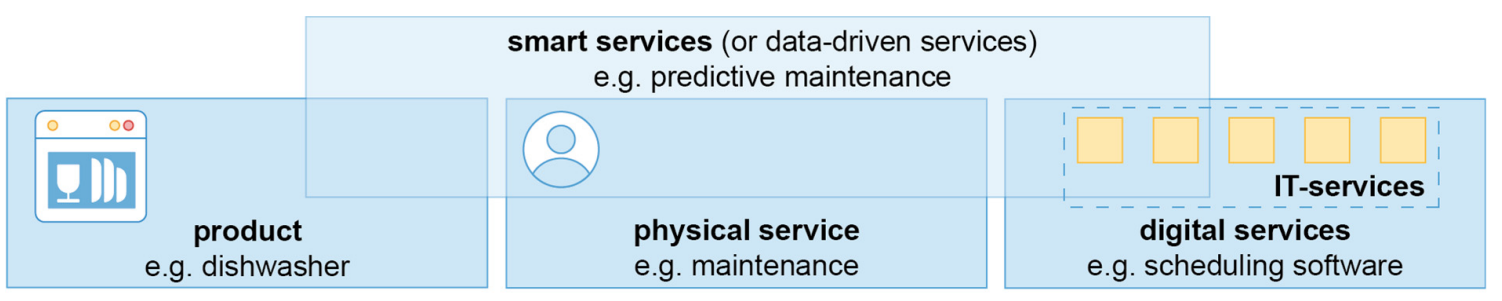

Figure 2. Smart services as bundles of a products and different types of services

Products are physical goods and the result of a production process. The benefit of the product is generated by fulfilling defined functions, whereby production and consumption take place at different points in time. Physical services are intangible goods that are primarily provided by a person in the physical environment. Supply and consumption take place simultaneously which means that storage is not possible and there is a direct contact with the customer (uno acto principle). The adjective "physical" refers to the place of provision and not to the nature of the service, which is non-physical. Digital services are provided in a digital environment and thus not (primarily) by people, but by IT-systems. Digital Services are bundles of IT-services, which in turn are software-based functions. Smart services are a combination of physical and digital services that are based on the data of a physical product. As a result smart services are also called data-driven services. Physical services are an optional part of a smart service and also a source for product-related data. Product-Service-Systems (PSS) are a combination of products and services, whereby services can be digital. This makes smart services a subset of PSS. Synonymous terms for PSS are hybrid service bundles and hybrid products.

\subsection{Perspectives of technical systems as enabler}

By integrating electronics and information technology, the functionality and capabilities of technical systems have been increased enormously. Mechatronic systems are characterised by the addition of 
sensors, information processing and actuators to the mechanical basic system, which makes it possible to control the systems during operation. In addition, a series of data on the system and its condition is generated, which form the basis for smart services. Advances in information and communication technology enable to solve fixed connection between sensors and actuators and to outsource data processing to IT-Systems. Functions can be completely outsourced making it easier and more flexible to bundle them. The integration of physical and virtual systems is expressed by the term Cyber-Physical Systems (CPS) (Broy et al., 2012). The reference architecture for CPS of Westermann et al. (2016) will serve as basis to an own architecture for smart services. The further development of the capabilities of technical systems leads to different perspectives, which are shown in Figure 3. One of the four perspectives are integrated product-service-systems with the ability to provide smart services.
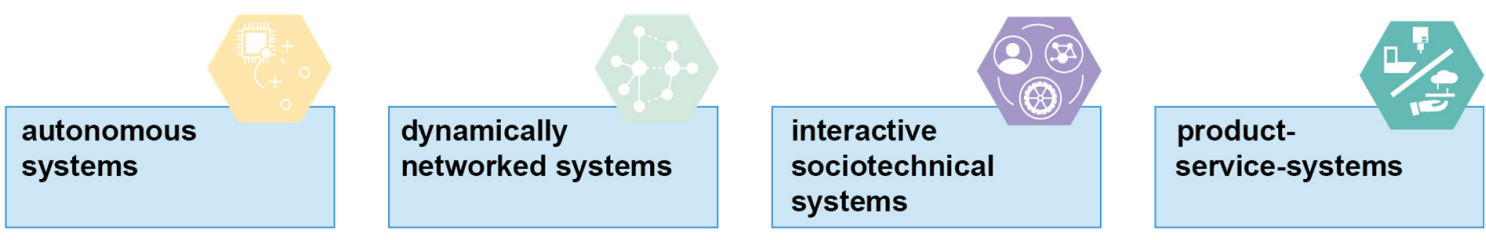

Figure 3. Perspectives of the development of technical systems

\subsubsection{Autonomous systems}

Systems solve complex tasks within a certain application domain. They must be able to act effectively without human help and learn during the operation about events and actions. These events and actions cannot be fully anticipated during the development of the systems. Numerous technological building blocks are still needed like cognition. The research question is how the systems can be reliably designed despite high uncertainty due to unknown situations in the life cycle.

\subsubsection{Dynamically networked systems}

Systems form complex systems whose functionality and performance exceeds that of the individual systems (local strategies). The systems change the system boundaries in operation (global setting) and together form a system of systems. The individual systems are developed independently and can operated independently of each other. The research question is how the design of the system can be controlled despite its integration into an unknown, dynamic system environment.

\subsubsection{Interactive socio-technical systems}

Systems intensify physical and cognitive interactions with its user. They adapt flexibly to the user's needs and support them in a context-based way. The systems can explain themselves and are based on multimodal interaction technologies (e.g. AR and holograms). The interaction of a system with its user is also used to provide digital services and to get back data from the user. The research question is, how users as subsystems can be taken into account when designing the systems.

\subsubsection{Product-service systems}

Systems are based on the close interaction of products and services to one market offering. The systems are designed for problem solving with services that are performed by the system itself as well as human resources. This leads to service-oriented business models like pay-per-use instead of buying the system at once. The research question is, how to integrate flexible service systems into the design process at an early stage and further development of existing products. This contribution is focussing on the further development of existing product with smart services. An additional research question is, how to find suitable, promising services for an existing product in order to generate value without changing the architecture of the whole product. 


\subsection{Evolution of the market offerings of manufacturing companies}

In addition to the further development of technical systems, the evolution of market offerings of manufacturing companies is a key driver for smart services. Markets are seeking other business models for different needs. In particular, ownership of products loses importance or for various reasons is not desired at all. On the other hand, companies see the opportunity to take over further value-added processes around their products, such as maintenance and consumables. The further development of the technical systems facilitates the close linking of the core product with other products and services. Smart services have the potential to provide products and services more easily. The evolution of manufacturing companies to services companies has been widely discussed (Baines et al., 2009) and also linked to the effect of digitization (Lerch and Gotsch, 2015). The focus of this contribution is to show the dependency of the evolution of the market offering and the technical realization of smart services based on the hypothesis that the revenue model is key element for the dependency. Figure 4 shows possible directions for the market offering with the examples of a company that produces dishwasher for professional use.

\begin{tabular}{|c|c|c|c|c|}
\hline product provider & solution provider & $\begin{array}{l}\text { value-added } \\
\text { services }\end{array}$ & $\begin{array}{c}\text { product } \\
\text { as a service }\end{array}$ & $\begin{array}{c}\text { XaaS } \\
\text { on platforms }\end{array}$ \\
\hline $\begin{array}{l}\text { Focus on offering } \\
\text { innovative products. }\end{array}$ & $\begin{array}{l}\text { Focus on offering } \\
\text { solutions based on } \\
\text { an core product. }\end{array}$ & $\begin{array}{l}\text { Focus on offering } \\
\text { physical and smart } \\
\text { services around the } \\
\text { product. }\end{array}$ & $\begin{array}{l}\text { Focus on operating } \\
\text { the product with } \\
\text { different services } \\
\text { and offering its use. }\end{array}$ & $\begin{array}{l}\text { Focus on offering } \\
\text { products and } \\
\text { services on own or } \\
\text { external platforms. }\end{array}$ \\
\hline \multicolumn{5}{|c|}{ Examples } \\
\hline Dishwasher & $\begin{array}{l}\text { Dishwasher with } \\
\text { suitable inserts for } \\
\text { different applications } \\
\text { and dishes. }\end{array}$ & $\begin{array}{l}\text { Commissioning of } \\
\text { the system and } \\
\text { automatic reordering } \\
\text { of detergent. }\end{array}$ & $\begin{array}{l}\text { Operating the } \\
\text { dishwasher with the } \\
\text { revenue model } \\
\text { „pay-per-cycle" }\end{array}$ & $\begin{array}{l}\text { Offering products } \\
\text { and services on a } \\
\text { platform for washing } \\
\text { and cleaning }\end{array}$ \\
\hline
\end{tabular}

Figure 4. Evolution of the market offerings of manufacturing companies

\subsubsection{From product to solution provider}

The change from product to solution provider is based on the market potential that customers need further products and services for the manufactured core product. Examples of products include spare parts, extensions and tools. Consulting is the most important service for a solution provider. In this way, a solution can be design including own products and services but also integrating third party products and services.

\subsubsection{Value-added services}

Value-added services are more closely linked to the product. On the one hand, this can be done contractually, such as through maintenance or service contracts. On the other hand, smart services are technically linked to the product and make it very easy to purchase them. An example is a companyspecific app or a function directly at the product (e. g. Amazon Dash), which can be used to reorder consumables like detergent. The automatic reordering by the system is also a profitable service for customer binding. In addition, it is technically possible to offer smart services that are linked to a product from another company. This can become a threat to a company with no services if other companies skim off sales potential and fill the customer interface with their services.

\subsubsection{Product as a service}

The next step is to offer the core product as a service. This enables a company to bundle its own products and services into a solution which is inseparable. Customers buy the value they get by using the bundled products and services. This approach follows the hypothesis that people do not want to buy the product, but what they can do with it. The further development of technical systems enables to operate own products more effectively and efficiently at the customer's premises. The idea of operating a system for someone else is not new, but can be implemented much more profitably with a bundle of smart services 
and a service-oriented revenue model like pay-per-use. Examples of services include remote monitoring, interactive instructions, predictive maintenance and remote maintenance.

\subsubsection{Everything as a service (XaaS) on platforms}

The technical progress makes it possible to offer products and services more flexibly and spontaneously and to share them. This leads to the paradigm of everything as a service (XaaS). Physical products are reduced to their functions, and many functions are then digitized and transferred to central IT systems (clouds). Functions can be purchased as services and used ad hoc if they are offered on digital platforms. Digital platforms are used to deploy outsourced functions (software-defined platforms) and to easily offer the functions as a service (trading platforms). Products are then the interface between customers and platforms. A well-known example are mobile phones as an interface for Appstores. Such platforms have already changed a number of industries and are likely to change the manufacturing industry.

\subsection{Adapting the revenue model}

The evolution of the market offering and the capabilities of smart service require an adaption of the revenue model as part of the business model (Meier et al., 2011). The predominant revenue model in the manufacturing industry is product-oriented: Revenues are generated through the sale of products with a one-off payment. If smart services are offered as a single service for a product or the entire product is offered as a service, a one-off payment is no longer possible or does not fully leverage the sales potential. It makes sense or is necessary to adapt the revenue model. Service-oriented revenue models refer the price to the input or output that is generated for the customer (Tukker, 2004). The different product- and service-oriented revenue models are illustrated in Figure 5.

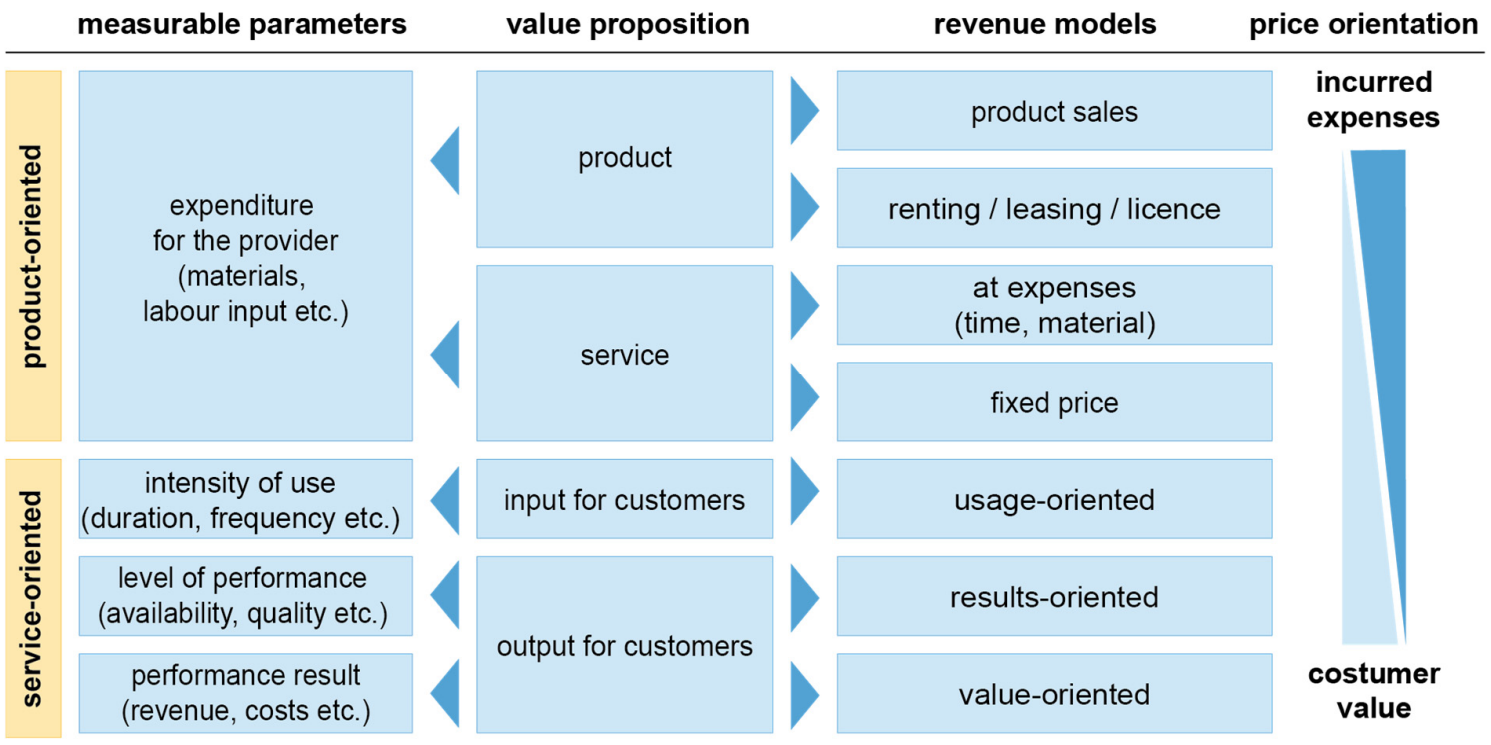

Figure 5. Characteristics of product and service-oriented revenue models (Bonnemeier et al., 2010)

It becomes clear that the revenue model, and thus the business model in general, are essential components of innovative market offerings. On the one hand, there are new revenue potentials and a safeguarding of the customer interface when smart services are offered with a corresponding revenue model. On the other hand, services and revenue models have to be integrated into the product design due to its technical dependencies. Depending on the type of service, certain revenue models are useful or necessary. And depending on a chosen revenue model, certain functions or services are required. For example, parameters have to be measured and transmitted in order to enable a correct billing. It is useful 
to implement certain services that reduce the costs of operation or the risk of failure, as the responsibility lies with the manufacturer respectively provider when a service-oriented business model is chosen.

\section{Status quo in research and practice}

In practice, there are already a few examples of how companies have already implemented smart service from which recurring elements can be derived. Research in the area of product development is intensively concerned with the topic of product service systems, but few have focused on smart services.

\subsection{Existing approaches in research}

The research approaches can be divided into approaches for reference architectures and reference solutions. Well-known approaches for an architecture come from Porter and Heppelmann (2015) with a technology stack, and from Kagermann et al. (2015) with a layer model showing the technical and organizational implementation both at a high level. The market perspective is considered in the technology-oriented framework for product service systems (PSS) from Schenkl et al. (2014), which propose a top-down approach to the planning of PSS starting with a solution layer. Riegg et al. (2016) propose a reference model based on the level of intelligence of the service system. Wünderlich et al. (2015) structure smart services based on four target groups (individual users, groups, companies). Adrodegari et al. (2016) show an approach for the planning of business models for product service systems, which do not consider the technical implementation in more detail. Fundamental principles for designing promising data-driven business models are carried out by Schaefer et al (2017). Bullinger et al. (2003) describe different views for service engineering with dimensions potential, process, result and market as design perspectives which include both the technology and market perspective.

\subsection{Case study}

Based on the literature an empirical study was made in order to find recurring elements and connections between that elements. On the basis of theoretical approaches, a first reference architecture was designed and further improved by means of the empirical study. In addition recurring building blocks were derived which should help to design new services based on an individual product and situation.

\begin{tabular}{|l|l|}
\hline \multicolumn{1}{|c|}{ company and product } & \multicolumn{1}{c|}{ smart service } \\
\hline Thyssen Krupp Elevator & $\begin{array}{l}\text { MAX is a Cloud-based maintenance solution that enables predictive } \\
\text { maintenance. Service technicians are notified in time when components } \\
\text { need to be replaced before they fail. }\end{array}$ \\
\hline RollsRoyce & $\begin{array}{l}\text { TotalCare covers the provision of the performance of an aircraft engine. } \\
\text { Services are its installation, remote monitoring, maintenance and repair. The } \\
\text { customer pays by flight hours. }\end{array}$ \\
\hline Product: Aircraft Engines & $\begin{array}{l}\text { Tirecare is a bundle of three services. Tirelog is an monitoring service for } \\
\text { small fleets. iCheck is a predictive maintenance solution for large fleets. } \\
\text { iManage is a complete solution for an optimized tire management. }\end{array}$ \\
\hline Michelin & $\begin{array}{l}\text { Kärcher Fleet is a smart service for the organisation of cleaning machinery. Cleaning } \\
\text { staff get informations regarding the location, date and duration of use, performance } \\
\text { and condition of the cleaning machines. }\end{array}$ \\
\hline Kroduct: Tires & $\begin{array}{l}\text { Tip Trailer Services represents a bundle of smart services for rental trailers, which } \\
\text { includes maintenance (Fleetcare), an fleet management service (Fleetmanage) and } \\
\text { fleet consulting for optimization (Fleetadvice). }\end{array}$ \\
\hline Product: Cleaning Machines & \multicolumn{1}{|c|}{ the study includes ten further cases } \\
\hline Product: Trailer & \\
\hline
\end{tabular}

Figure 6. Excerpt from the case studies of existing smart services 


\section{Planning of smart services with a reference architecture}

The proposed approach is divided into the two parts of the reference architecture and planning support through the consistency assessment of recurring modules.

\subsection{Reference architecture}

The proposed reference architecture is based on the idea of the Business Model Canvas, which presents a complex issue in a simple and descriptive way to promote creativity in further development (Osterwalder and Pigneur, 2010). Figure 7 shows an overview of the reference architecture which contains elements for both the technology and the market perspective to allow an integrative planning of a new market offerings.

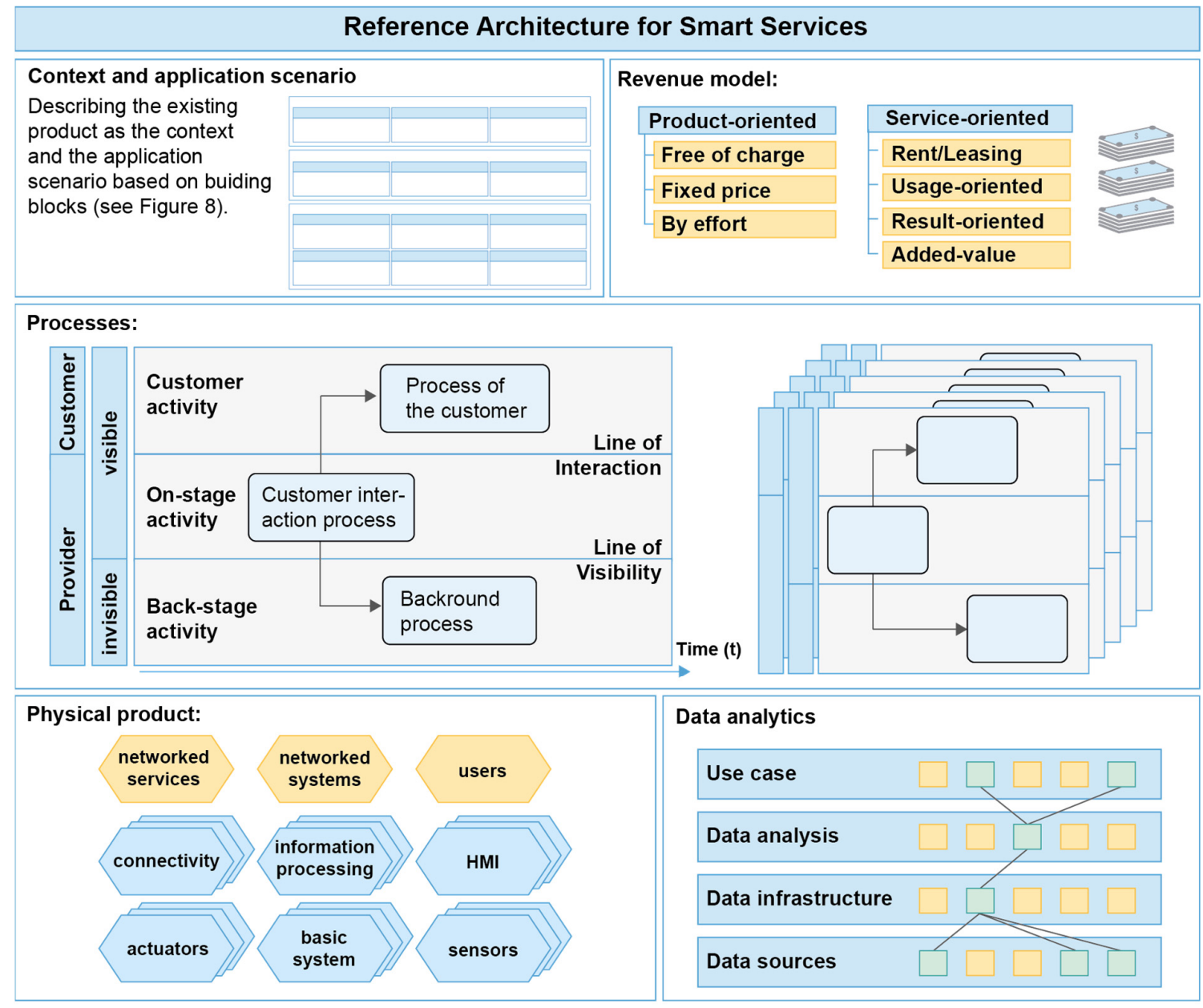

Figure 7. Reference architecture for smart services

\subsubsection{Context and application scenarios}

The context and the application scenario can be defined by using building blocks. Through the empirical study and existing approaches in literature, recurring building blocks were defined from which application scenarios can be derived. Figure 8 shows the defined building blocks which are sorted by its level of generated value and complexity. The existing product is described as the context since it is one of the main constrains and its architecture usually should be changed as less as possible. Furthermore it is important to specify recurrent situation of users of the product in order to identify potentials for new services. 


\begin{tabular}{|c|c|c|}
\hline \multicolumn{3}{|l|}{ visualization } \\
\hline consulting & instruction and training & self-service \\
\hline $\begin{array}{l}\text { Advice before and during the use } \\
\text { phase regarding product and } \\
\text { process. }\end{array}$ & $\begin{array}{l}\text { Instructions and training for the } \\
\text { construction, use and dismantling of } \\
\text { the product. }\end{array}$ & $\begin{array}{l}\text { Interactive instructions for } \\
\text { maintenance and repair of the } \\
\text { product. }\end{array}$ \\
\hline \multicolumn{3}{|l|}{ monitoring and instructions } \\
\hline monitoring & note and warning & service support \\
\hline $\begin{array}{l}\text { Preparation of data concerning the } \\
\text { product based on sensors and } \\
\text { external sources. }\end{array}$ & $\begin{array}{l}\text { Notes and warnings based on } \\
\text { predefined rules and data regarding } \\
\text { the product. }\end{array}$ & $\begin{array}{l}\text { Preparation of maintenance/repair } \\
\text { by means of preliminary reports }\end{array}$ \\
\hline \multicolumn{3}{|l|}{ assistance } \\
\hline updates and upgrades & planning support & remote access \\
\hline $\begin{array}{l}\text { Transfer of updates and upgrades to } \\
\text { improve and extend the product. }\end{array}$ & $\begin{array}{l}\text { Suggestions for time and resource } \\
\text { planning. }\end{array}$ & $\begin{array}{l}\text { Access to the product or its control } \\
\text { by other systems. }\end{array}$ \\
\hline prediction & automated ordering & automated optimization \\
\hline $\begin{array}{l}\text { Prediction of future probable } \\
\text { conditions and errors. }\end{array}$ & $\begin{array}{l}\text { Automated ordering of consumables } \\
\text { and spare parts. }\end{array}$ & $\begin{array}{l}\text { Automated implementation of } \\
\text { optimization measures in the } \\
\text { process. }\end{array}$ \\
\hline
\end{tabular}

Figure 8. Building blocks for smart services

\subsubsection{Revenue model}

As described in the section above, the revenue model plays a crucial role since there are strong dependencies on technical implementation. Depending on the selected application scenario, revenue models can be useful or even necessary. If a decision is first made for a revenue model, then useful or necessary application scenarios arise which are to be implemented.

\subsubsection{Processes}

The service processes represent the concept of customer interaction. Different approaches to process visualisation can be used as a form of presentation, whereby the service blueprinting approach focuses on customer interaction (Bitner et al., 2008). The involvement of the user is an essential element as users can provide useful data on which services are based. For each building block are standard processes defined which can be also used as building blocks.

\subsubsection{Physical product}

Smart services are part of a Cyber Physical system. Accordingly, a corresponding architecture can be used for the representation. The CPS is a data provider with regard to its own state and the state of the environment. The focus here is on sensor technology and networking with systems and user in the environment in order to receive data. Collected data is transferred to IT systems (clouds) to enable central data networking and processing. The deployment of digital services is then carried out again on the basis of the human-maschine-interface (HMI) to the users.

\subsubsection{Data analytics}

Many services are based on data analytics application in order to integrate intelligence into the services and making it "smart". To design data analytics applications the Analytics Canvas of Kuehn et al. (2018) is used which is a semi-formal specification technique for describing analytics use cases, the necessary infrastructure as well as requirements for each domain. The approach is based on four layers beginning with understanding the problem and analyse the domain which lead to the analytics use cases. The second step is to analyse the data to define data sources like sensors or file systems. The third step is to define where to store the data (data pools). The last step is to define what shall be done with the data like prediction of condition, solving a problem or automate a process like reordering of consumables. The concept based on this canvas can be used for the detailed implementation. 


\subsection{Planning support based on consistency matrices}

There are two scenarios for extending a product with smart services. First, further development of technical systems enables new services (technology push, see paragraph 2.2). Second, changes of user preferences lead to a higher demand for new business models (market pull, see paragraph 2.3). Depending on the scenario there are two direction to build up the architecture (top down and buttom up) but still many possibilities to plan a new market offering. The building blocks for each element of the architecture are assessed regarding their consistency, which leads to a restriction of the solution space. Figure 9 shows the initial scenarios for planning new services. The consistency matrices can be used for both scenarios since they are undirected.

Scenario 1: New capabilities

of technical systems

\section{technology push}

- High-performance and cheaper sensors

- Easy connectivity

- Outsourcing of data processing to clouds

- New possibilities of

Human-Machine-Interface

Scenario 2: Adapting business models with focus on revenue models

,

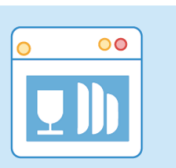

Product

consistency matrices

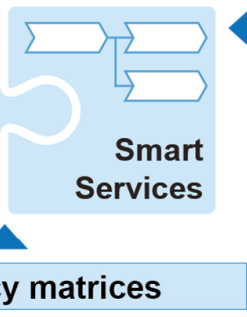

\begin{tabular}{|l|l|l|l|l|l|}
\hline & & & & \\
\hline & & \\
\hline & & \\
\hline
\end{tabular}
Consistency between

the elements of the

architecture to restrict

the solution space

\section{market pul}

- Markets are seeking for products as a service ("using instead of owning")

- Market offerings need to be placed on own or external platforms

Figure 9. Planning of smart services for manufacturing companies

\subsubsection{Technology push}

The scenario describes the situation where a company would like to implement smart services to an existing products in order to its increase value. However, it is not known yet which services exactly. The objective is to implement obvious services and increase the value of market performance without extensive implementation work. The input variable are the capabilities of the existing product regarding sensor technology, connectivity, HMI and existing data regarding the system and its environment. From there it is possible to consider which building blocks, processes and data analytics applications can be implemented with the existing system. The strategy is to quickly leverage obvious potentials and to raise the value of the existing product without changing it completely. The procedure is to build the architecture from bottom up.

\subsubsection{Market pull}

The scenario describes the situation in which a company wants to implement a particular revenue or business model, or plans to implement certain application scenarios for smart services. During the planning phase, the objective is to quickly and precisely identify which service processes, product changes and data analytics applications are required. The input variable is a company's decision to implement a specific business model with a corresponding revenue model. The architecture is then built from top to bottom. First, suitable building blocks are combined for an application scenario that matches the selected revenue model. Based on this, service processes can be defined, changes to the product specified and a concept for data analysis developed.

\subsubsection{Consistency matrix}

Based on the interrelationship between the individual elements of the architecture, the consistency between the elements can be evaluated in order to restrict the solution space. For this purpose, a consistency assessment is carried out which evaluates the consistency of pairs of elements on a scale of 
one to five against each other. The consistency refers to the economic sense as well as the technical dependencies and feasibility. A rating of five means that it is advisable to use both elements in one solution. A rating of one means that the two elements should not be used in a solution. During the planning of new services this leads to further suitable elements being identified or inappropriate elements being excluded based on the already chosen elements for a new solution. Figure 10 shows the result of the evaluation between the elements of the application scenarios and the revenue model where the economic sense of purpose is given priority.

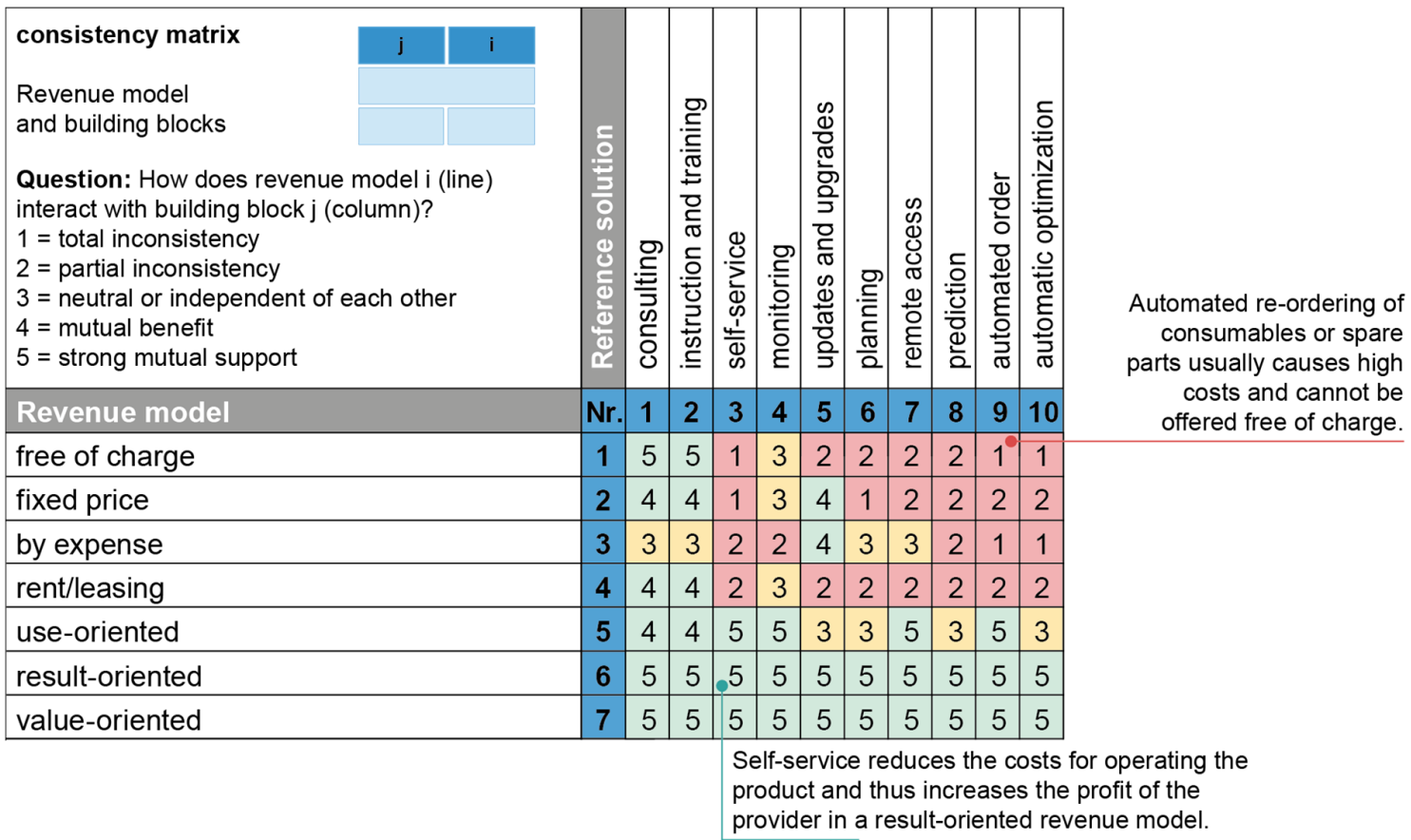

Figure 10. Consistency matrix as planning support

An evaluation of the physical product against the application scenarios focuses on the technical dependencies. In other words, which sensor technology is required for which application scenario, or which sensor technology can be used to easily implement which scenarios. A set of standard characteristics has been defined for all elements of the architecture, which creates a building blocks for the entire architecture. This means that planning on the basis of the consistency assessment can be carried out from the two perspectives technology push and market pull. The evaluation forms the basis for a configurator that can be used for IT-supported planning. A similar and promising approach for IT support for product-service system planning can be found at Sakao et al. (2009) who are focussing on product-service systems in general which could be applied to smart services based on the suggested architecture.

\section{Conclusion and outlook}

The planning of smart service must include a technology and market perspectives, since the revenue model respectively business model plays a crucial role in generating the value for users. The concept of the reference architecture thus allows a top-down (market pull) and buttom-up (technology push) planning. Using the canvas approach, a clear planning architecture is created. The assessment of the consistency of individual building blocks makes it possible to narrow down the solution space and thus support the planning. The next steps are the development of a modular system based on the first consistency evaluation and existing modules in order to provide a comprehensive planning support. Another focus is the identification of usable data in a data map, as data acquisition plays a crucial role in the buttom up procedure and designing data analytics use cases. 


\section{References}

Adrodegari, F., Saccani, N. and Kowalkowski, C. (2016), “A Framework for PSS Business Models: Formalization and Application", Procedia CIRP, Vol. 47, pp. 519-524. https://doi.org/10.1016/j.procir.2016.03.073

Allmendinger, G. and Lombreglia, R. (2005), "Four Strategies for the Age of Smart Services", Harvard Business Review, Vol. 83 No. 10, pp. 131-146.

Baines, T., Lightfoot, H., Benedettini, O. and Kay, J. (2009), "The servitization of manufacturing: A review of literature and reflection on future challenges", Journal of Manufacturing Technology Management, Vol. 20 No. 5, pp. 547-567. https://doi.org/10.1108/17410380910960984

Bitner, M.J., Ostrom, A.L. and Morgan, F.N. (2008), "Service Blueprinting - A Practical Technique for Service Innovation”, California Management Review, Vol. 50 No. 3, pp. 66-94. https://doi.org/10.2307/41166446

Bonnemeier, S., Burianek, F. and Reichwald, R. (2010), "Revenue models for integrated customer solutions: Concept and organizational implementation", Journal of Revenue \& Pricing Management, Vol. 9 No. 3, pp. 228-238. https://doi.org/10.1057/rpm.2010.7

Broy, M., Cengarle, M.V. and Geisberger, E. (2012), "Cyber-Physical Systems: Imminent Challenges", Proceedings of the 17th Monterey Workshop, Oxford, UK, March 19-21, 2012, Springer, Berlin, Heidelberg, pp. 1-28. https://doi.org/10.1007/978-3-642-34059-8_1

Bullinger, H.-J., Fähnrich, K.-P. and Meiren, T. (2003), "Service engineering - methodical development of new service products", International Journal of Production Economics, Vol. 85 No. 3, pp. 275-287. https://doi.org/10.1016/S0925-5273(03)00116-6

Herterich, M.M., Uebernickel, F. and Brenner, W. (2015), “The Impact of Cyber-physical Systems in Industrial Services in Manufacturing", Procedia CIRP, Vol. 30, pp. 323-328. https://doi.org/10.1016/j.procir.2015.02.110

Kagermann, H., Riemensperger, F., Hoke, D., Helbig, J., Stocksmeier, D. et al. (2015), Smart Service Welt Recommendations for the Strategic Initiative Web-based Services for Businesses, acatech - National Academy of Science and Engineering, Germany, Berlin.

Kuehn, A., Joppen, R., Reinhart, F., Roeltgen, D., von Enzberg, S. and Dumitrescu, R. (2018), “Analytics Canvas - A Framework for the Design and Specification of Data Analytics Projects", Proceedings of 28th CIRP Design conference, Nantes, France, May 23-25, 2018. (submitted)

Kuhlenkoetter, B., Wilkens, U., Bender, B., Abramovici, M., Sueße, T. et al. (2017), "New Perspectives for Generating Smart PSS Solutions - Life Cycle, Methodologies and Transformation", Procedia CIRP, Vol. 64, pp. 217-222. https://doi.org/10.1016/j.procir.2017.03.036

Lerch, C. and Gotsch, M. (2015), "Digitalized Product-Service Systems in Manufacturing Firms a Case Study Analysis”, Research - Technology Management, Vol. 58 No. 5, pp. 45-52. https://doi.org/10.5437/08956308X5805357

Meier, H., Voelker, O. and Funke, B. (2011), "Industrial Product-Service Systems (IPS2) - Paradigm shift by mutually determined products and services", International Journal of Advanced Manufacturing Technology, Vol. 52 No. 9-12, pp. 1175-1191. https://doi.org/10.1007/s00170-010-2764-6

Osterwalder, A. and Pigneur, Y. (2010), Business Model Generation: A Handbook for Visionaries, Game Changers, and Challengers, Wiley and Sons, New Jersey.

Porter, M. and Heppelmann, J. (2015), "How Smart, Connected Products Are Transforming Companies", Harvard Business Review, Vol. 93 No. 10, pp. 96-114.

Riegg, A., Klose, M., Matei, A., Reinfurt, L., Ditze, M. and Hudert, S. (2016), A Conceptual Reference Model for Smart Services - Whitepaper, SOA Innovation Lab e.V., Bonn, Germany.

Sakao, T., Shimomura, Y., Sundin, E. and Comstock, M. (2009), "Modeling design objects in CAD system for Service/Product Engineering”, Computer-Aided Design, Vol. $41 \quad$ No. 3, pp. 197-213. https://doi.org/10.1016/j.cad.2008.06.006

Schaefer, D., Walker, J. and Flynn, J. (2017), “A Data-driven Business Model Framework for Value Capture in Industry 4.0”, Proceedings of the ICMR 2017 / 15th International Conference on Manufacturing Research, Vol. 6, Greenwich, UK, September 5-7, 2017, IOS Press, Amsterdam, Netherlands, pp. 245-250. https://doi.org/10.3233/978-1-61499-792-4-245

Schenkl, S.A., Sauer, R.M. and Mörtl, M. (2014), “A Technology-centered Framework for Product-Service Systems”, Proceedia CIRP, Vol. 16, pp. 295-300. https://doi.org/10.1016/j.procir.2014.01.029 
Tukker, A. (2004), "Eight Types of Product-Service System: Eight Ways to Sustainability? Experiences from Suspronet", Business Strategy and the Environment, Vol. 13 No. 4, pp. 246-260. https://doi.org/10.1002/bse.414

Westermann, T., Anacker, H., Dumitrescu, R. and Czaja, A. (2016), "Reference Architecture and Maturity Levels for Cyber-Physical Systems", Proceedings of the 2nd IEEE International Symposium on Systems Engineering, Edinburgh, Scotland, October 3-5, 2016, IEEE. https://doi.org/10.1109/SysEng.2016.7753153

Wünderlich, N., Heinonen, K., Ostrom, A., Patricio, L., Sousa, R. et al. (2015), "Futurizing smart service: implications for service researchers and managers", Journal of Services Marketing, Vol. 29 No. 6/7, pp. 442447. https://doi.org/10.1108/JSM-01-2015-0040

Martin Rabe, Master of Science

Fraunhofer IEM, Product- and Productionmanagement

Zukunftsmeile 1, 33102 Paderborn, Germany

Email: martin.rabe@iem.fraunhofer.de 